\title{
REVIEW ON VEIN ENHANCEMENT METHODS FOR BIOMETRIC SYSTEM
}

\author{
Suhaimi Yusoff ${ }^{1}$, Abdul Rahman Ramli ${ }^{2}$, Shaiful Jahari Hashim ${ }^{3}$, Fakhrul Zaman Rokhani ${ }^{4}$ \\ ${ }^{1}$ Lecturer, Electronics Technology Department, UniKL British Malaysian Institute, Selangor, Malaysia \\ ${ }^{2}$ Associate Professor, Department of Computer and Communication System Engineering, Universiti Putra Malaysia, \\ Selangor, Malaysia \\ ${ }^{3}$ Senior Lecterur, Department of Computer and Communication System Engineering, Universiti Putra Malaysia, \\ Selangor, Malaysia \\ ${ }^{4}$ Senior Lecterur, Department of Computer and Communication System Engineering, Universiti Putra Malaysia, \\ Selangor, Malaysia
}

\begin{abstract}
Vein biometric system uses vein inside human body as a unique identification. Researchers have concluded that human vein pattern is unique to an individual. Vein pattern cannot be stolen or duplicated because it is in the human body. At present, vein pattern in finger, palm, palm-dorsa and wrist of human are used for biometric system. This paper presents a review on vein enhancement methods. This paper begins with overview of vein detection and the advantages of vein as biometric modal. Next, the vein capturing technology to obtain the vein pattern in human body is presented. Finally, preceding works related to vein enhancement methods are discussed and reviewed
\end{abstract}

Keywords: biometric, vein, vein detection, vein enhancement, vein pattern. ****

\section{INTRODUCTION}

Nowadays, people are concerned about security. People are faced with the risk of stolen or guessed password and personal identification number (PIN number) and stolen or faked card. Thus, biometric authentication technology has attracted or preferred as a security technology. Vein authentication technology is very secure because vein is exist inside human body. Therefore, it cannot be stolen or guessed compared to password or card.

Vein biometric uses the vein pattern inside the human body as a personal identification tool. Using infra-red (IR), reflected or transmitted images of blood vessel of a hand or other part of the body are captured by a CCD image sensor. The red blood cells that existed in the blood vessel will absorb the IR light and forms as a darker image compared to the surrounding structures where it shows up as brighter image as shown in Fig. 1. The image further processed by image processing techniques to produce the extracted vein pattern. This extracted vein pattern then can be stored as a template in database for authentication purpose.

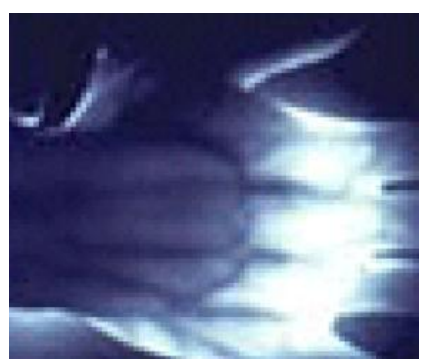

Fig -1: Vein image example

\subsection{Advantages of Vein Biometric}

Vein extremely difficult to forge - vein pattern is beneath human body, thus it is difficult to steal or replicate. Bloods also need to flow when capturing the vein image. So, unauthorized person or thief cannot simply cut finger or hand of a person for unmannered use. Researchers have determined that the vein pattern of human body is unique to an individual, even for identical twins and remain unchanged over people age.

Vein needs special device to capture vein image and the person can notice if thief attempts to steal the vein image. While fingerprint can be stolen by duplicate it using gummy fingers. Hand geometry, iris and face also can be obtained using camera without noticeable from the individual himself. Users do not need to touch the sensor device. This offers hygienic and can increase user acceptance. Compared to fingerprint, users need to touch the sensor device during authentication process. Fingerprint and hand geometry can wear away due to work places such as factories and constructions sites and place with inferior environment. Iris authentication needs for person apply with direct light into their eyes. This can bring uncomfortable feel for some peoples.

\section{VEIN CAPTURE TECHNOLOGY}

IR imaging systems are used in various fields. IR imaging is also capable of capturing vein patterns inside human body. Thus, researchers use this technology to obtain human vein pattern for biometric application. The IR light can penetrate through human tissues about $3 \mathrm{~mm}$ depth and the 
haemoglobin will absorb more IR light then the surrounding tissues. This cause the veins appear as dark in the IR image [1].

\subsection{Near-IR and Far-IR}

There are two IR imaging technologies available at present to obtain the vein pattern in human body. These two imaging technologies are near-IR and far-IR imaging.

Far-IR imaging technology is suitable for capturing the large vein pattern in the palm-dorsa. It has difficulties in capturing vein in the palm and wrist. It is also sensitive to ambient conditions and human body condition, thus does not provide a stable image quality. Also, most of the far-IR images have low levels of contrast, which make it hard to separate veins from the background [1].

Near-IR imaging technology is suitable for capturing vein pattern in palm-dorsa, palm and wrist. It is more tolerant to changes in environmental and body condition such as airconditioned and outdoor environment. However, the defects on the skin surface are also visible in the image such as hairs. This will cause problem in the digital image to be processed [1].

\subsection{Vein Capture Method}

There are 3 methods to capture vein pattern image, which is light reflection, light transmission and side lighting method.

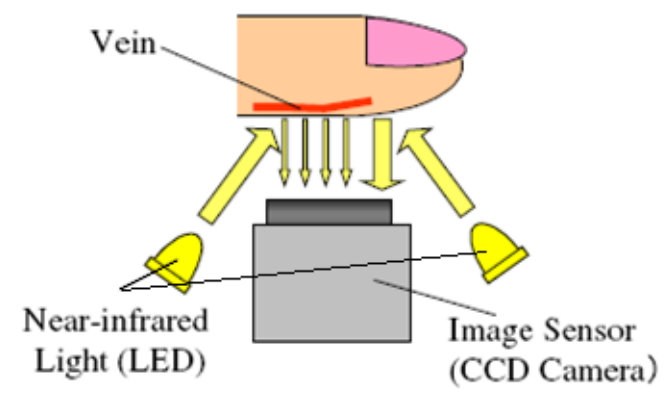

Fig -2: Light reflected method [2]

As shown in the Fig. 2, light reflection method uses the reflected IR light to capture the vein pattern. The IR source is placed side by side with the CCD image sensor, while the hand or finger is placed in front of the image sensor. This method usually is used to capture vein at palm, palm-dorsa or wrist. Since these parts of human body are large enough, the IR cannot pass through it. So, light reflected is the best way to capture vein at these parts. This method has major advantage for the end product design because the IR source and image sensor can be packed together to make the product compact. On the other hand, the effects of reflection from all parts of the human body such as skin and the shallow penetration of IR light under the skin makes the contrast very low. Thus, this requires advance image processing technique because the differences between vein and other parts is very small and hard to segment it especially the thin vein [2].

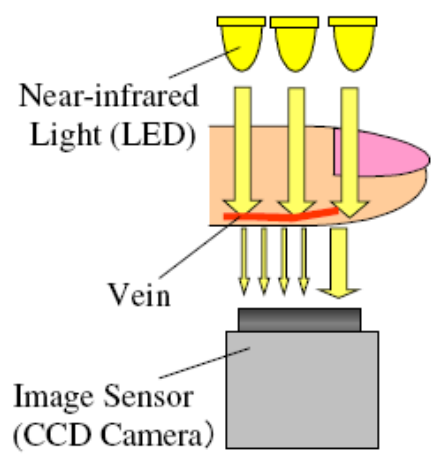

Fig -3: Light transmission method [2]

In the light transmission method, the hand or finger is placed in between the IR source and image sensor as shown in the Fig. 3. The IR light that passes through the hand or finger will be captured by a CCD image sensor at the other end. Since this method requires IR light to pass through the human body, only body parts with appropriate thickness can be used to capture the vein pattern [2].

As there is no effect of reflection in this method, it produces a high contrast vein image compared to the light reflection method. A high contrast image does not need advanced image processing techniques as required by the light reflection method, but the drawback is the end product will be slightly bigger especially using palm or palm-dorsa as biometric modal [2].

Hashimoto [2] had introduced a third method called side lighting. This method places the IR sources on both side of the finger. The IR light from both sides will go through the finger, scatters inside the finger, and then pass through at the other side of the finger before captured by the image sensor. This method is shown in Fig. 4. This method also produces high contrast vein pattern images. The end product for this method will be slightly bigger compared to light reflection method but smaller compared to light transmission method [2].

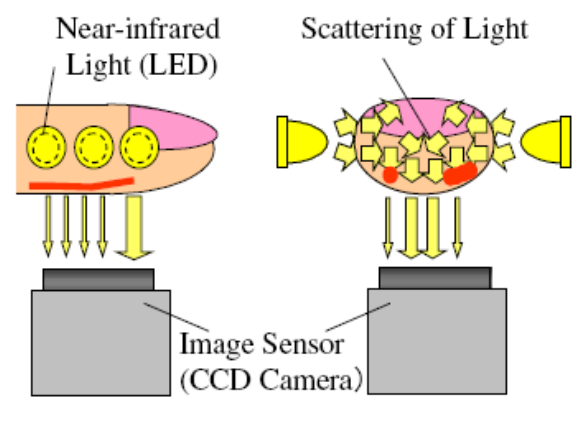
(a) Side View
(b) Front View

Fig -4: Side lighting method [2]

Kato et al [3] have developed penetration and reflection type vein capture devices. For penetration vein capture device, they developed an automatic light intensity adjustment device to resolve difficulty due to the thickness of human skin, body fat and substances of different persons is different. With this they get $99.98 \%$ authentication rate. For 
reflection type vein capture device, they experiment with different angles and concluded that 75 degree is the optimum angle for their reflection vein capture device. For this, they get $98.82 \%$ authentication rate.

\subsection{Vein Capture Light Source Control Method}

Due to the thickness human skin, body fat and substances of different persons are difference, the vein images quality of different persons that are acquired at the same light intensity is difference from each other. So, researchers have come out with a control device or method for the image acquisition to get best vein image quality.

Kato et al [3] have developed an automatic light intensity adjustment device by control and apply a voltage to the light source by feeding back captured vein image. They proposed an algorithm for the adjustment by counting pixel numbers with reference to threshold value and increase or decrease the light intensity accordingly.

$\mathrm{Xu}$ et al [4] and Lee et al [5] proposed adaptive illumination control based on image quality assessment. The quality of the captured vein image is assessed using two-dimensional entropy and the light intensity is adjusted based on the assessment result. To control the light intensity, a buck converter circuit is designed to drive the light through Pulse Width Modulation (PWM) technique.

Zhao and Sheng [6] proposed a quantitative evaluation for vein image quality based on mean and variance with the drive current of the infrared light source. From their research, they get optimal evaluation for vein image is $96 \%$ when the drive current of infrared light source is $0.59 \mathrm{~A}$.

Qin et al [7] proposed vein image quality assessment using local quality of different blocks using an average Radon transform. A local quality score is estimated for each block according to the curvature in its Radon space, based on which a global quality score is assessed for vein image.

\section{PRECEEDING WORKS}

Vein enhancement also called as pre-processing is a process that is applied before the recognition process. The main objective of vein enhancement is to make the vein that has been captured by camera more visible by applying image processing technique such as noise remover, make the illumination better and etc. This is to ensure the quality of subsequent process which is feature extraction and matching. If the vein quality is better quality, the recognition process also will be more accurate and efficient. After supressed the noise, it will be segmented to separate the vein with the background by using different methods including threshold, line tracking, edge based, region based, watershed and etc.

\subsection{Prior Works}

In this section, we reviewed the prior works on vein enhancement methods.

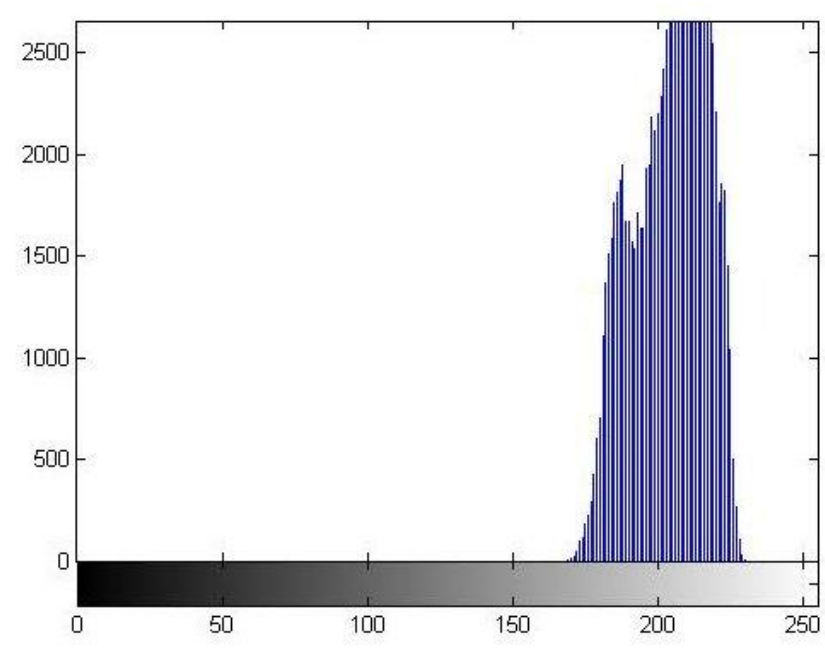

Fig -5: Histogram of a vein image

Fig. 5 shows the histogram of a vein image. From the histogram, it can be summarized that the dynamic range of the vein image is not well distributed along all the pixels. Zhou and Kumar [8], El-sayed and Abdel-Khalek [9], Gu [10], Li et al [11], Liu and Song [12], Pal and Jasutkar [13], Pi et al [14], Prasanna et al [15], Ramsoful and Khan [16] and Uriarte-Antonio et al [17] have used histogram equalization in their method to enhance the contrast of the vein image. However, the drawback of this method it also can increase the contrast of background noise, while decreasing the usable information. Liu [18] then used adaptive histogram equalization but this method tendency to over amplify small amount of noise in the image. Lu et al [19], Prabhakar and Thomas [20], Rossan and Khan [21], Wang et al [22] and Mahri et al [23] used contrast limited adaptive histogram equalization (CLAHE) to overcome the weakness of the adaptive histogram equalization. Yakno et al [24] then combined CLAHE with Fuzzy Histogram Hyperbolization to further enhance the quality of vein image.

Image normalization typically will be used as the first process. Each time the vein image is captured, the light intensity, human body thickness and surrounding will contribute to the difference of image greyscale distribution in an image. Although it is the same vein, every time the vein is captured, the vein image will have difference greyscale value. So, the vein images will be normalized to images that have the same greyscale distribution and enhance the contrast of the vein image. General normalization technique is good enough to normalize an image. However, this general normalization technique is not efficient enough to get a proper normalize image. Wang et al [25] improved the general normalization method by controlling the desired mean and variance of a normalize image. However the improved general normalization from Wang et al [25] can segment the vein image properly if the illumination distribution is uniform, but in non-uniform distribution, it cannot segment it properly [26]. Then, Zhao et al [26] has improved the method to have better segmentation and connectivity result. However, it cannot estimate the threshold efficiently if the vein is unclear in 
which resultant the vein is not properly detected. Gu [10], Kang and Wu [27], Li et al [11], Park and Kim [28], Sheng et al [29], Uriarte-Antonio et al [17], Wang et al [30], Wu et al [31], Wang et al [32], Wu et al [31], Yang et al [33], Yu et al [34], Liu et al [35], Mahri et al [23] and Wu et al [36] have used normalization technique as part of their enhancement method.

For noise removal, Gaussian filter and median filter are typically used to remove noise in a vein image. Gu [10], Park and Kim [28], Ramsoful and Khan [16], Rossan and Khan [21], Song et al [37], Uriarte-Antonio et al [17], Wang and Chen [38], Wu et al [31], Ding et al [39], Liu [18], Mansoor et al [40], Prabhakar and Thomas [20], Yang et al [41], Yang et al [33], Yun-peng et al [42] and Mekyska et al [43] have used both Gaussian filter and median filter together or separately in their method. Gaussian filter has been used to smooth and enhance the noisy vein image. For the general Gaussian filter, the image noise such as fine wrinkles also extracted from the process [44]. Due to this problem, Lee et al [45], You et al [44] and Asaari et al [46] used symmetrical modified Gaussian low filter for image enhancement. Median filter can eliminate burrs and reduce the unwanted flaw. This noise usually removed according to the size of noise in the vein image [39], [34]. Usually Gabor filter has been used as feature extraction method [47], [48], [49], [50], [51], [52], [53], [54], [55]. But Gabor filter can also be used as noise remover. Yu et al [34], Yang et al [56], Shi and Yang [57], Yang and Shi [58] and Prabhakar and Thomas [20] have used Gabor filter for noise remover in their image enhancement method. However, Gabor filter involved a lot of calculation [44].

For segmentation, Im et al [59] proposed an improved vascular pattern extraction on palm-dorsa. The algorithm is a direction based vascular pattern extraction based on the directional information of vein pattern. Two filters is applied to the vein image, row vein pattern filter for effective extraction of the abscissa vein pattern and column vein pattern extraction filter for effective extraction of the ordinate vein pattern. Then the outputs from both filters are combined to get final vein pattern.

Miura et al [60] extracted finger vein pattern by tracing the vein texture. To extract the finger vein pattern from vein pattern image, a method by using repeated line tracking that start from various positions is proposed. However, this algorithm has slightly high mismatch ratio when cold or winter because the vein image of the finger is unclear. Yang et al [61] then improved the repeated line tracking which improve the vein connectivity.

Miura et al [62] then proposed Maximum Curvature Points which analyze the brightness changes in vein image profile. The method extracted the centerlines of the veins by searching for positions where the curvatures of a crosssectional profile of a vein image are locally maximal..

Wang and Leedham [1] proposed a novel technique that utilizes the morphological watershed algorithm to extract the skeletonization vein pattern from the original vein images. However, the algorithm fails to skeletonize if two veins too close or unclear. Kejun et al [63] improved the watershed and combined it with region merging. This improved the performance of the algorithm.

Zhang et al [64] invented a multiscale feature extraction method of finger vein pattern based on wavelet and local interconnection structure neural network. Zhao et al [65] used wavelet thresholding based on Besov norm regularization to remove noise. Redhouane et al [66] also used wavelet for feature extraction. Li et al [11] come up with enhancement method based on wavelet to enhance the contrast and also removed noise from vein image. The method consists of normalization, wavelet decomposition, noise remover, wavelet transform, histogram equalization and Gabor filter.

Generally there are global and local threshold segmentation techniques. Global threshold technique used global threshold as a reference for thresholding. Due to this reason, the global threshold result is not satisfactory enough. Local threshold technique calculates threshold value at each pixel, resulting in better segmentation. Ding et al [39], Wang [25], $\mathrm{Yu}$ and Qin [67], Khalil-Hani et al [68], Zhang and Hu [69], Lee and Park [70], Wu et al [31], Liu [18], Wu et al [36], Hongxing et al [71], Yun-peng et al [42] and You et al [44] used local dynamic threshold segmentation method which is simple and effective. However, Zhao et al [26] discovered that by using this method, image with non-uniform distribution will result in loss of connection in the vein pattern. Zhao et al [26] improved the local dynamic threshold segment method by refining the standard deviation calculation in the algorithm. The disadvantage of this method is the processing speed is slow due to computation.

$\mathrm{Yu}$ and Qin [67] proposed an enhanced method for extracting finger vein based on fuzzy theory algorithm. Using the fuzzy theory and combined the image segmentation algorithm with concave detection algorithm, $\mathrm{Yu}$ and Qin come out with an enhanced method for extracting finger vein features.

Yusoff et al [72] has proposed vein enhancement method using Difference of Gaussian (DoG) and threshold to segment the vein image. The DoG comprise of subtraction of blurred version of an original image from a less blurred version of the original. Kang et al [73] then proposed Difference of Gaussian-Histogram Equalization (DoG-HE). This method improves the clearness and contrast vein image. They concluded that the DoG filter is efficient when the ratio of the two different Gaussian kernels is typically $4: 1$ or $5: 1$. Then they used histogram equalization to increase the contrast of the vein.

Wang and Chen [38] proposed a specially designed filter using Laplacian of Gaussian (LoG) to suppress the noise and for edge detection. Then they used median filter to remove the noise from the LoG. 
For thinning, Zhang and Suen [74] proposed fast parallel thinning algorithm. This algorithm is fast and required simple computations. Wang and Leedham [1] and KhalilHani and Eng [68] have used this algorithm for thinning. Ding et al [39] reported that the advantage of the conditional thinning algorithm is the connected points of lines, the turning points of the poly line and the T type breakouts can be coherent with the original image. Ding et al [39] and Yu et al [34] improved this algorithm to remove the un-single pixel point in vein image. Yun-peng et al [42] has used this improved algorithm for their thinning.

Table 1 shows some of the vein enhancement methods proposed by researchers. From Table 1, it can be concluded that various method have been proposed to enhance the vein image before recognition process.

Table -1: Vein enhancement methods

\begin{tabular}{|c|c|}
\hline Authors & Enhancement Method \\
\hline $\begin{array}{l}\text { Zhou and } \\
\text { Kumar [8], } \\
\text { EL-sayed et } \\
\text { al [9] }\end{array}$ & Histogram equalization. \\
\hline $\begin{array}{l}\text { Ding et al } \\
\text { [39] }\end{array}$ & $\begin{array}{l}\text { Threshold image method-Median filter - } \\
\text { Improved conditional thinning. }\end{array}$ \\
\hline $\begin{array}{l}\text { Kejun et al } \\
{[63]}\end{array}$ & Watershed - Region merging. \\
\hline $\begin{array}{lll}\text { Cao } & \text { et } & \text { al } \\
{[75]} & & \end{array}$ & $\begin{array}{l}\text { Even-symmetric Gabor filter - } 2 \mathrm{D} \\
\text { convolution - Multiscale multiplication } \\
\text { rule. }\end{array}$ \\
\hline $\begin{array}{l}\text { Chunyi et al } \\
\text { [76] }\end{array}$ & $\begin{array}{l}\text { Matched filter based on maximum } \\
\text { curvature. }\end{array}$ \\
\hline $\mathrm{Gu}[10]$ & $\begin{array}{l}\text { Normalization - Gaussian filter - } \\
\text { Elliptic high pass filter - Histogram } \\
\text { equalization. }\end{array}$ \\
\hline $\begin{array}{ll}\text { Guan } & \text { et al } \\
{[77],} & \text { Guan } \\
\text { and } & \text { Yang } \\
{[78]} & \end{array}$ & $\begin{array}{l}\text { Combination filters to remove noise - } \\
\text { Local dynamic threshold. }\end{array}$ \\
\hline $\begin{array}{l}\text { Han and Lee } \\
{[48]}\end{array}$ & $\begin{array}{l}\text { Estimated background illumination - } \\
\text { Subtracting the background illumination } \\
\text { from original image. }\end{array}$ \\
\hline $\begin{array}{l}\text { Kang et al } \\
{[73]}\end{array}$ & $\begin{array}{l}\text { Difference of Gaussian filter (ratio is } \\
4: 1 \text { ) - Histogram equalization. }\end{array}$ \\
\hline Li et al [11] & $\begin{array}{l}\text { Normalization - Wavelet decomposition } \\
\text { - Threshold denoise - Wavelet } \\
\text { transform - Histogram equalization - } \\
\text { Gabor filter. }\end{array}$ \\
\hline Liu [18] & $\begin{array}{l}\text { Adaptive histogram equalization - } \\
\text { Median filter and winner filter - Gray } \\
\text { linear transformation - Improved } \\
\text { Niblack method for segment. }\end{array}$ \\
\hline $\begin{array}{l}\text { Liu and Song } \\
{[12]}\end{array}$ & $\begin{array}{l}\text { Segmentation based on the peak values } \\
\text { of the horizontal projection of the image } \\
\text { - Canny operator with locally adaptive } \\
\text { threshold - Multi-resolution method - } \\
\text { Histogram equalization. }\end{array}$ \\
\hline Liu et al [79] & Multi-resolution method. \\
\hline Lu et al [19] & Multi-resolution method - Contrast \\
\hline
\end{tabular}

limited adaptive histogram equalization (CLAHE).

\begin{tabular}{|l|l|}
\hline $\begin{array}{l}\text { Mansoor et } \\
\text { al [40] }\end{array}$ & Median filter - Adaptive threshold. \\
\hline $\begin{array}{l}\text { Asaari et al } \\
\text { [46] }\end{array}$ & $\begin{array}{l}\text { Modified Gaussian Filter (MGF) } \\
\text { technique from [45]. }\end{array}$ \\
\hline $\begin{array}{l}\text { Pal and } \\
\text { Jasutkar [13] }\end{array}$ & $\begin{array}{l}\text { Histogram equalization - Threshold - } \\
\text { Hough transform. }\end{array}$ \\
\hline Pi et al [14] & $\begin{array}{l}\text { Edge-preserving filter - Elliptic high } \\
\text { pass filter - Histogram equalization. }\end{array}$ \\
\hline $\begin{array}{l}\text { Prabhakar } \\
\text { and Thomas } \\
\text { [20] }\end{array}$ & $\begin{array}{l}\text { Median filter - Contrast Limited } \\
\text { Adaptive Histogram Equalization } \\
\text { (CLAHE) - Maximum Curvature }\end{array}$ \\
$\begin{array}{l}\text { Extraction method - Gabor filter - } \\
\text { Thinning. }\end{array}$ \\
\hline Hrastogram equalzation of high boost
\end{tabular}

Prasanna et Histogram equalization of high boost al [15] $\quad$ filtering.

Ramsoful Histogram equalization - Median filter and Khan Gaussian filter - Local adaptive [16] threshold - Median filter and Gaussian filter - Erosion and dilation for thinning.

\begin{tabular}{|c|c|}
\hline $\begin{array}{l}\text { Rossan and } \\
\text { Khan [21] }\end{array}$ & $\begin{array}{l}\text { Contrast limited adaptive histogram } \\
\text { equalization (CLAHE) - Threshold (use } \\
\text { various algorithm) - Median filter - Low } \\
\text { pass Gaussian filter - Wiener filter. }\end{array}$ \\
\hline $\begin{array}{l}\text { Sheng et al } \\
{[29]}\end{array}$ & Normalization. \\
\hline $\begin{array}{l}\text { Song et al } \\
{[37]}\end{array}$ & $\begin{array}{l}\text { Segmentation using the mean curvature } \\
\text { and Laplacian - Symmetric Gaussian } \\
\text { filter. }\end{array}$ \\
\hline $\begin{array}{l}\text { Uriarte- } \\
\text { Antonio et al } \\
{[17]}\end{array}$ & $\begin{array}{l}\text { Histogram equalization - Median filter - } \\
\text { Gaussian low pass filter - } \\
\text { Normalization - Local threshold - } \\
\text { Modification of the Fast Parallel } \\
\text { Algorithm for thinning from [74]. }\end{array}$ \\
\hline $\begin{array}{l}\text { Wang et al } \\
{[30]}\end{array}$ & $\begin{array}{l}\text { Normalization - Retinex method - } \\
\text { Adaptive filtering. }\end{array}$ \\
\hline $\begin{array}{l}\text { Wang and } \\
\text { Chen [38] }\end{array}$ & $\begin{array}{l}\text { High-boost filter - Bi-level threshold - } \\
\text { Gaussian filter - Laplacian of Gaussian } \\
\text { (LoG) - Median filter. }\end{array}$ \\
\hline $\begin{array}{l}\text { Wang et al } \\
{[25]}\end{array}$ & $\begin{array}{l}\text { Gray scale normalization - Local } \\
\text { dynamic threshold - Remove noises } \\
\text { according to the size of it - Combination } \\
\text { method of general conditional thinning } \\
\text { and templates. }\end{array}$ \\
\hline $\begin{array}{l}\text { Wang et al } \\
{[22]}\end{array}$ & $\begin{array}{l}\text { Contrast limited adaptive histogram } \\
\text { equalization (CLAHE) - Wiener low- } \\
\text { pass filter. }\end{array}$ \\
\hline $\begin{array}{l}\text { Wang et al } \\
{[32]}\end{array}$ & 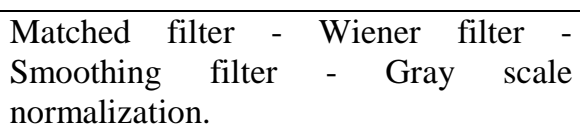 \\
\hline
\end{tabular}




\begin{tabular}{|c|c|}
\hline $\begin{array}{l}\text { Zhang et al } \\
\text { [64] }\end{array}$ & $\begin{array}{l}\text { Multiscale self-adaptive enhancement } \\
\text { transform based on the wavelet. }\end{array}$ \\
\hline Wu et al [31] & $\begin{array}{l}\text { Grayscale normalization - Gaussian } \\
\text { filter - Median filter - Local dynamic } \\
\text { threshold - NiBlack method - Median } \\
\text { filter - Thinning. }\end{array}$ \\
\hline $\begin{array}{l}\text { Yakno et al } \\
{[24]}\end{array}$ & $\begin{array}{l}\text { Combination of CLAHE with Fuzzy } \\
\text { Histogram Hyperbolization. }\end{array}$ \\
\hline $\begin{array}{l}\text { Yang et al } \\
{[41]}\end{array}$ & $\begin{array}{l}\text { Modified non-linear method from [80] - } \\
\text { Median filter. }\end{array}$ \\
\hline $\begin{array}{l}\text { Yang et al } \\
{[33]}\end{array}$ & $\begin{array}{l}\text { Normalization - Local threshold - } \\
\text { Median filter. }\end{array}$ \\
\hline $\begin{array}{l}\text { You et al } \\
{[44]}\end{array}$ & $\begin{array}{l}\text { Gaussian low pass filter - Niblack } \\
\text { method. }\end{array}$ \\
\hline $\begin{array}{l}\text { Yun-peng et } \\
\text { al [42] }\end{array}$ & $\begin{array}{l}\text { Niblack method - Median filter - } \\
\text { Improved conditional thinning from } \\
{[39] .}\end{array}$ \\
\hline Yu et a & abor filter. \\
\hline $\begin{array}{l}\text { Fischer and } \\
\text { Rybnicek } \\
\text { [81] }\end{array}$ & $\begin{array}{l}\text { Global threshold }- \text { Border tracing } \\
\text { algorithm. }\end{array}$ \\
\hline $\begin{array}{l}\text { Mahri et al } \\
{[23]}\end{array}$ & lization - CLAHE. \\
\hline $\begin{array}{l}\text { Yang and } \\
\text { Shi [58] }\end{array}$ & $\begin{array}{l}\text { Scattering removal }- \text { Directional } \\
\text { filtering method based on a family of } \\
\text { Gabor filters. }\end{array}$ \\
\hline Lee et al [45] & ter \\
\hline
\end{tabular}

\section{CONCLUSION}

Vein authentication systems record subcutaneous IR absorption patterns to produce unique and private identification templates for users. Researchers have determined that the vein pattern of the human body is unique to a specific individual and does not change as people age. Vein has many advantages because it uses features that inside human body rather than on the surface. This modality is very secure because vein is exists inside human body.

In this paper, the theories and related works to the vein enhancement were reviewed. It discussed the theories related to vein biometric technology, advantages and vein capture method. Then related works in vein enhancement method from other researchers also has been presented.

\section{ACKNOWLEDGEMENTS}

The authors wish to deepest thanks to all people who have been very helpful and provided guidance to complete this journal.

\section{REFERENCES}

[1] L. Wang and G. Leedham, "Gray-Scale Skeletonization of Thermal Vein Patterns Using the Watershed Algorithm in Vein Pattern Biometrics," 2006 Int. Conf. Comput. Intell. Secur., pp. 1597 1602, Nov. 2006.

[2] J. Hashimoto, "Finger Vein Authentication Technology and Its Future," in 2006 Symposium on VLSI Circuits, 2006. Digest of Technical Papers., 2006, vol. 00, no. c, pp. 5-8.

[3] T. Kato, M. Kondo, K. Hattori, R. Taguchi, M. Hoguro, and T. Umezaki, "Development of penetrate and reflection type finger vein certification," in 2012 International Symposium on MicroNanoMechatronics and Human Science (MHS), 2012, pp. 501-506.

[4] J. Xu, C. Jianjiang, X. Dingyu, and P. Feng, "Near infrared vein image acquisition system based on image quality assessment," in 2011 International Conference on Electronics, Communications and Control (ICECC), 2011, no. 61005032, pp. 922-925.

[5] Y. H. Lee, M. Khalil-Hani, and R. Bakhteri, "FPGAbased finger vein biometric system with adaptive illumination for better image acquisition," 2012 Int. Symp. Comput. Appl. Ind. Electron., no. Iscaie, pp. 107-112, Dec. 2012.

[6] Y. Zhao and M. Sheng, "Application and analysis on quantitative evaluation of hand vein image quality," 2011 Int. Conf. Multimed. Technol., pp. 5749-5751, Jul. 2011.

[7] H. Qin, S. Li, A. C. Kot, and L. Qin, "Quality Assessment of Finger-vein Image," in Asia-Pacific Signal \& Information Processing Association Annual Summit and Conference (APSIPA ASC) 2012, 2012, no. c, pp. 1-4.

[8] Y. Zhou and A. Kumar, "Human Identification Using Palm-Vein Images," IEEE Trans. Inf. Forensics Secur., vol. 6, no. 4, pp. 1259-1274, Dec. 2011.

[9] M. A. El-sayed, S. F. Bahgat, and S. Abdel-Khalek, "New Approach for Identity Verification System Using the Vital Features Based on Entropy," Int. J. Comput. Sci. Issues, vol. 10, no. 6, pp. 11-17, 2013.

[10] X. Gu, "A method for hand vein recognition based on Curvelet Transform phase feature," Proc. 2011 Int. Conf. Transp. Mech. Electr. Eng., pp. 1693-1696, Dec. 2011.

[11] B. Li, X. Yang, and Z. Chen, "Study of Fusion Iterative Enhancement Algorithm of Hand Vein Image Based on Wavelet Transfor," 2012 Fifth Int. Symp. Comput. Intell. Des., pp. 54-56, Oct. 2012.

[12] Z. Liu and S. Song, "An embedded real-time fingervein recognition system for mobile devices," IEEE Trans. Consum. Electron., vol. 58, no. 2, pp. 522527, May 2012.

[13] M. M. Pal and R. W. Jasutkar, "Implementation of Hand Vein Structure Authentication Based System," 2012 Int. Conf. Commun. Syst. Netw. Technol., pp. 114-118, May 2012. 
[14] W. Pi, J. Shin, and D. Park, "An effective quality improvement approach for low quality finger vein image," 2010 Int. Conf. Electron. Inf. Eng., vol. 1, no. Iceie, pp. V1-424-V1-427, Aug. 2010.

[15] R. D. Prasanna, P. Neelamegam, S. Sriram, and N. Raju, "Enhancement of Vein Patterns in Hand Image for Biometric and Biomedical Application using Various Image Enhancement Techniques," Procedia Eng., vol. 38, pp. 1174-1185, Jan. 2012.

[16] P. Ramsoful and M. Heenaye-Mamode Khan, "Feature extraction techniques for dorsal hand vein pattern," Third Int. Conf. Innov. Comput. Technol. (INTECH 2013), pp. 49-53, Aug. 2013.

[17] J. Uriarte-Antonio, D. Hartung, J. E. S. Pascual, and R. Sanchez-Reillo, "Vascular biometrics based on a minutiae extraction approach," in 2011 Carnahan Conference on Security Technology, 2011, pp. 1-7.

[18] C. Liu, "A new finger vein feature extraction algorithm," 2013 6th Int. Congr. Image Signal Process., no. Cisp, pp. 395-399, Dec. 2013.

[19] Y. Lu, S. J. Xie, S. Yoon, and D. S. Park, "Finger vein identification using polydirectional local line binary pattern," 2013 Int. Conf. ICT Converg., pp. 61-65, Oct. 2013.

[20] P. Prabhakar and T. Thomas, "Finger Vein Identification Based on Minutiae Feature Extraction with Spurious Minutiae Removal," 2013 Third Int. Conf. Adv. Comput. Commun., pp. 196-199, Aug. 2013.

[21] I. Rossan and M. H.-M. Khan, "Impact of Changing Parameters when Preprocessing Dorsal Hand Vein Pattern," Procedia Comput. Sci., vol. 32, pp. 513520, 2014.

[22] Y. Wang, Y. Fan, W. Liao, K. Li, L.-K. Shark, and M. R. Varley, "Hand vein recognition based on multiple keypoints sets," 2012 5th IAPR Int. Conf. Biometrics, pp. 367-371, Mar. 2012.

[23] N. Mahri, S. A. Sundi Suandi, and B. A. Rosdi, "Finger Vein Recognition Algorithm Using Phase Only Correlation," in 2010 International Workshop on Emerging Techniques and Challenges for HandBased Biometrics, 2010, pp. 1-6.

[24] M. Yakno, J. M. Saleh, and B. A. Rosdi, "Low contrast hand vein image enhancement," 2011 IEEE Int. Conf. Signal Image Process. Appl., pp. 390-392, Nov. 2011.

[25] K. Wang, Y. Zhang, Z. Yuan, and D. Zhuang, "Hand Vein Recognition Based on Multi Supplemental Features of Multi-Classifier Fusion Decision," 2006 Int. Conf. Mechatronics Autom., pp. 1790-1795, Jun. 2006.

[26] S. Zhao, Y. Wang, and Y. Wang, "Extracting hand vein patterns from low-quality images: A new biometric technique using low-cost devices," Proc. 4th Int. Conf. Image Graph. ICIG 2007, pp. 667-671, 2007.

[27] W. Kang and Q. Wu, "Contactless Palm Vein Recognition Using a Mutual Foreground-Based Local Binary Pattern," IEEE Trans. Inf. Forensics Secur., vol. 6013, no. c, pp. 1-1, 2014.
[28] G.-T. Park and S.-W. Kim, "Embedded processor optimised for vascular pattern recognition," IET Circuits, Devices Syst., vol. 7, no. 2, pp. 81-92, Mar. 2013.

[29] M.-Y. Sheng, Y. Zhao, F.-Q. Liu, Q.-D. Hu, D.-W. Zhang, and S.-L. Zhuang, "Acquisition and Preprocessing of Hand Vein Image," 2011 Fourth Int. Symp. Knowl. Acquis. Model., pp. 251-253, Oct. 2011.

[30] H.-B. Wang, L. Tao, and J. Zhou, "Novel algorithm for hand vein feature extraction and recognition based on vertical integral projection and wavelet decomposition," 2012 2nd Int. Conf. Consum. Electron. Commun. Networks, vol. 2, pp. 1928-1931, Apr. 2012.

[31] W. Wu, F. Lu, G. Cheng, and C. Shi, "A Vein Based Biometric Experiment and Some New Developments," 2012 Third Glob. Congr. Intell. Syst., no. c, pp. 131-135, Nov. 2012.

[32] Y. Wang, K. Li, and J. Cui, "Hand-dorsa vein recognition based on partition Local Binary Pattern," IEEE 10th Int. Conf. SIGNAL Process. Proc., pp. 1671-1674, Oct. 2010.

[33] W. Yang, Q. Rao, and Q. Liao, "Personal Identification for Single Sample Using Finger Vein Location and Direction Coding," 2011 Int. Conf. Hand-Based Biometrics, pp. 1-6, Nov. 2011.

[34] C.-B. Yu, H.-F. Qin, L. Zhang, and Y.-Z. Cui, "Finger-vein image recognition combining modified hausdorff distance with minutiae feature matching," J. Biomed. Sci. Eng., vol. 02, no. 04, pp. 261-272, 2009.

[35] F. Liu, G. Yang, Y. Yin, and S. Wang, "Singular value decomposition based minutiae matching method for finger vein recognition," Neurocomputing, vol. 145, pp. 75-89, Dec. 2014.

[36] Z. Wu, Y. Zhou, X. Hu, M. Zhou, X. Dai, X. Li, and D. Wang, "A vein image enhancement algorithm for the multi-spectral illumination," 2013 IEEE Int. Conf. Imaging Syst. Tech., pp. 332-336, Oct. 2013.

[37] W. Song, T. Kim, H. C. Kim, J. H. Choi, H.-J. Kong, and S.-R. Lee, "A finger-vein verification system using mean curvature," Pattern Recognit. Lett., vol. 32, no. 11, pp. 1541-1547, Aug. 2011.

[38] J.-W. Wang and T.-H. Chen, "Building Palm Vein Capturing System for Extraction," 2011 21st Int. Conf. Syst. Eng., pp. 311-314, Aug. 2011.

[39] Y. Ding, D. Zhuang, and K. Wang, "A study of hand vein recognition method," in IEEE International Conference Mechatronics and Automation, 2005, 2005, vol. 4, no. July, pp. 2106-2110.

[40] M. Mansoor, S. N. Sravani, I. Badshah, and M. Saleem, "Real-time low cost infrared vein imaging system," in 2013 International Conference on Signal Processing , Image Processing \& Pattern Recognition, 2013, pp. 117-121.

[41] J. Yang, Y. Shi, and J. Yang, "Personal identification based on finger-vein features," Comput. Human Behav., vol. 27, no. 5, pp. 1565-1570, Sep. 2011. 
[42] H. Yun-peng, W. Zhi-yong, Y. Xiao-ping, and X. Yu-ming, "Hand vein recognition based on the connection lines of reference point and feature point," Infrared Phys. Technol., vol. 62, pp. 110-114, Jan. 2014.

[43] J. Mekyska, X. Font-Aragones, M. Faundez-Zanuy, R. Hernandez-Mingorance, A. Morales, and M. A. Ferrer-Ballester, "Thermal hand image segmentation for biometric recogniton," in 2011 Carnahan Conference on Security Technology, 2011, no. 1, pp. $1-5$.

[44] L. You, X. Li, L. Sun, and F. Li, "Finger Vein Recognition Method Based on Gaussian Low-Pass Filter and Direction Detection," 2014 Int. Conf. Inf. Commun. Technol. (ICT 2014), pp. 2.055-2.055, 2014.

[45] E. C. Lee, H. Jung, and D. Kim, "New finger biometric method using near infrared imaging," Sensors, vol. 11, no. 3, pp. 2319-2333, Jan. 2011.

[46] M. S. Mohd Asaari, S. a. Suandi, and B. A. Rosdi, "Fusion of Band Limited Phase Only Correlation and Width Centroid Contour Distance for finger based biometrics," Expert Syst. Appl., vol. 41, no. 7, pp. 3367-3382, Jun. 2014.

[47] J. Zhang, T. Tan, and L. Ma, "Invariant texture segmentation via circular Gabor filters," 2002 16th Int. Conf. Pattern Recognit., vol. 2, no. 2, pp. 901904, 2002.

[48] W.-Y. Han and J.-C. Lee, "Palm vein recognition using adaptive Gabor filter," Expert Syst. Appl., vol. 39, no. 18, pp. 13225-13234, Dec. 2012.

[49] S. J. Xie, L. Yu, and D. S. Park, "Guided Gabor Filter for Finger Vein Pattern Extraction," 2012 Eighth Int. Conf. Signal Image Technol. Internet Based Syst., pp. 118-123, Nov. 2012.

[50] Z. Wang, B. Zhang, W. Chen, and Y. Gao, "A Performance Evaluation of Shape and Texture Based Methods for Vein Recognition," 2008 Congr. Image Signal Process., no. 1, pp. 659-661, 2008.

[51] J.-C. Lee, "A novel biometric system based on palm vein image," Pattern Recognit. Lett., vol. 33, no. 12, pp. 1520-1528, Sep. 2012.

[52] W. Yang, X. Huang, and Q. Liao, "Fusion of finger vein and finger dorsal texture for personal identification based on Comparative Competitive Coding," in 2012 19th IEEE International Conference on Image Processing, 2012, pp. 11411144.

[53] W. Yang, X. Huang, F. Zhou, and Q. Liao, "Comparative competitive coding for personal identification by using finger vein and finger dorsal texture fusion," Inf. Sci. (Ny)., vol. 268, pp. 20-32, Jun. 2014.

[54] J. Yang and X. Zhang, "Feature-level fusion of global and local features for finger-vein recognition," IEEE 10th Int. Conf. SIGNAL Process. Proc., pp. 1702-1705, Oct. 2010.

[55] J. Yang and Y. Shi, "Finger-vein ROI localization and vein ridge enhancement," Pattern Recognit. Lett., vol. 33, no. 12, pp. 1569-1579, Sep. 2012.
[56] J. Yang, Y. Shi, J. Yang, and L. Jiang, “A novel finger-vein recognition method with feature combination," in Proceedings - International Conference on Image Processing, ICIP, 2009, pp. 2709-2712.

[57] Y. Shi and J. Yang, "Image restoration and enhancement for finger-vein recognition," 2012 IEEE 11th Int. Conf. Signal Process., vol. 10, pp. 1605-1608, Oct. 2012.

[58] J. Yang and Y. Shi, "Towards finger-vein image restoration and enhancement for finger-vein recognition," Inf. Sci. (Ny)., vol. 268, no. 07, pp. 3352, Jun. 2014.

[59] S. K. Im, H. S. Choi, and S.-W. Kim, "A DirectionBased Vascular Pattern Extraction Algorithm for Hand Vascular Pattern Verification," ETRI J., vol. 25, no. 2, pp. 101-108, Apr. 2003.

[60] N. Miura, A. Nagasaka, and T. Miyatake, "Feature extraction of finger-vein patterns based on repeated line tracking and its application to personal identification," Mach. Vis. Appl., vol. 15, pp. 194203, 2004.

[61] W. Yang, X. Yu, and Q. Liao, "Personal authentication using finger vein pattern and fingerdorsa texture fusion," Proc. seventeen ACM Int. Conf. Multimed. - MM '09, p. 905, 2009.

[62] N. Miura, A. Nagasaka, and T. Miyatake, "Extraction of finger-vein patterns using maximum curvature points in image profiles," IEICE Trans. Inf. Syst., vol. E90-D, pp. 1185-1194, 2007.

[63] W. Kejun, X. Xinyan, R. Zhen, and F. Bin, "Grayscale skeletonization of near-infrared vein patterns using the improved watershed algorithm in vein pattern biometrics," in 2009 4th IEEE Conference on Industrial Electronics and Applications, 2009, no. c, pp. 241-245.

[64] Z. B. Zhang, D. Y. Wu, S. L. Ma, and J. Ma, "Multiscale Feature Extraction of Finger-Vein Patterns Based on Wavelet and Local Interconnection Structure Neural Network," 2005 Int. Conf. Neural Networks Brain, vol. 2, pp. 1081-1084, 2005.

[65] S. Zhao, Y. D. Wang, and Y. H. Wang, "Biometric identification based on low-quality hand vein pattern images," Proc. 7th Int. Conf. Mach. Learn. Cybern. ICMLC, vol. 2, no. July, pp. 1172-1177, 2008.

[66] L. Redhouane, B. Sarah, and B. Abdelkader, "Dorsal hand vein pattern feature extraction with wavelet transforms," 2014 Int. Symp. Networks, Comput. Commun., pp. 1-5, Jun. 2014.

[67] C. Yu and H. Qin, "A research on extracting human finger vein pattern characteristics," Proc. World Congr. Intell. Control Autom., pp. 3783-3788, 2008.

[68] M. Khalil-Hani and P. C. Eng, "FPGA-based embedded system implementation of finger vein biometrics," 2010 IEEE Symp. Ind. Electron. Appl., no. Isiea, pp. 700-705, Oct. 2010.

[69] H. Zhang and D. Hu, "A Palm Vein Recognition System," in 2010 International Conference on Intelligent Computation Technology and Automation, 2010, pp. 285-288. 
[70] E. C. Lee and K. R. Park, "Image restoration of skin scattering and optical blurring for finger vein recognition," Opt. Lasers Eng., vol. 49, no. 7, pp. 816-828, Jul. 2011.

[71] S. Hongxing, L. Wang, and W. Jiayi, "Hand vein recognition technology based on region code," Proc. 2013 Int. Conf. Mechatron. Sci. Electr. Eng. Comput., pp. 1212-1215, Dec. 2013.

[72] S. Yusoff, A. R. Ramli, M. I. Saripan, and S. Mashohor, "Palm-Dorsa Vein Detection Using Webcam," in International Advanced of Technology Congress (ATCi), 2009, pp. 1-6.

[73] W. Kang, Y. Liu, Q. Wu, and X. Yue, "Contact-free palm-vein recognition based on local invariant features.," PLoS One, vol. 9, no. 5, p. e97548, Jan. 2014.

[74] T. Y. Zhang and C. Y. Suen, "A fast parallel algorithm for thinning digital patterns," Commun. ACM, vol. 27, no. 3, pp. 236-239, Mar. 1984.

[75] D. Cao, J. Yang, Y. Shi, and C. Xu, "Structure Feature Extraction for Finger-Vein Recognition," 2013 2nd IAPR Asian Conf. Pattern Recognit., vol. 1, pp. 567-571, Nov. 2013.

[76] L. Chunyi, L. Mingzhong, and S. Xiao, "A Finger Vein Recognition Algorithm Based on Gradient Correlation," AASRI Procedia, vol. 1, pp. 40-45, Jan. 2012.

[77] F. Guan, K. Wang, H. Mo, H. Ma, and J. Liu, "Research of Finger Vein Recognition Based on Fusion of Wavelet Moment and Horizontal and Vertical 2DPCA," in 2009 2nd International Congress on Image and Signal Processing, 2009, pp. $1-5$.

[78] F. Guan, K. Wang, and Q. Yang, "A study of two direction weighted (2D) ${ }^{2} \mathrm{LDA}$ for finger vein recognition," 2011 4th Int. Congr. Image Signal Process., pp. 860-864, Oct. 2011.

[79] Z. Liu, Y. Yin, H. Wang, S. Song, and Q. Li, "Finger vein recognition with manifold learning," J. Netw. Comput. Appl., vol. 33, no. 3, pp. 275-282, May 2010.

[80] Y. Shi, J. Yang, and R. Wu, "Reducing Illumination Based on Nonlinear Gamma Correction," in 2007 IEEE International Conference on Image Processing, 2007, no. 1, pp. I - 529-I - 532.

[81] S. T. M. Fischer, M. Rybnicek, "A NOVEL PALM VEIN RECOGNITION APPROACH BASED ON ENHANCED LOCAL GABOR BINARY PATTERNS HISTOGRAM SEQUENCE," Int. Conf. Syst. Signals Image Process., no. April, pp. 11-13, 2012.

\section{BIOGRAPHIES}

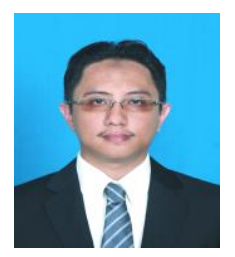

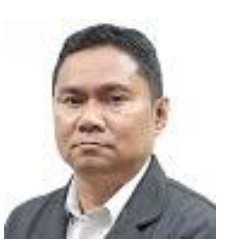

Abdul Rahman Ramli is Associate Professor at Universiti Putra Malaysia. His research interest in image processing, intelligent system and etc

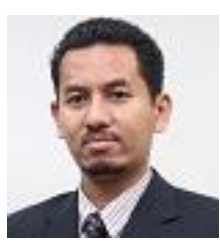

Shaiful Jahari Hashim is Senior Lecturer at Universiti Putra Malaysia. His research interest in radio frequency, microwave and etc.

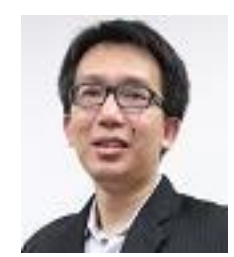

Fakhrul Zaman Rokhani is Senior Lecturer at Universiti Putra Malaysia. His research interest in embedded system. 